\title{
Potential of ATR-FTIR Spectroscopy for the Classification of Natural Resins
}

\author{
Pablo Martín-Ramos ${ }^{1 *}$, Ignacio Alonso Fernández-Coppel², Norlan Miguel Ruíz-Potosme³ ${ }^{3}$ Jesús Martín-Gil ${ }^{4}$
}

\begin{abstract}
This study reports evidence on the feasibility of a classification of natural resins by ATR-FTIR spectroscopy based on specific absorbance band positions. A set of twelve selected resins were used to assess band position variability and this vibrational data was put in relationship with the chemical composition of the resins. As a result, a classification of resins into the following four main families is proposed: 1) those correlated with communic acids (sandarac, black copal, pine pitch and amber); 2) those associated with abietic acid (rosin and mastic); 3) those with ketone groups (white copal, tragacanth and frankincense); and 4) those with ester groups (myrrh, shellac and propolis). This classification system may find application not only in facile quality control of natural products, but also for rapid characterization of cultural heritage materials.
\end{abstract}

Key words: Classification, FTIR, Resins, Vibrational characterization, terpenes.

\section{INTRODUCTION}

Resins are lustrous, brittle, transparent and hard substances which are normally orange, yellow or brown in colour. They are amorphous and break with conchoidal fracture, and burn away completely, giving smoky flames and aromatic smells. They are water insoluble, but dissolve in organic solvents such as turpentine, oil or petroleum spirits. Natural resins are of vegetable origin, being obtained from tree exudation or from insects secretions. ${ }^{1,2}$

\section{The different types of resins}

Notable examples of plant resins include black copal from the araucariaceae Agathis dammara, white copal (Copalcuáuitl) from Bursera jorullensis or Bursera linanoe, dammar gum from trees of the family Dipterocarpaceae, Dragon's blood from the dragon trees (Dracaena species), frankincense from Boswellia sacra, gum guaiacum from the lignum vitae trees of the genus Guaiacum, mastic (plant resin) from the mastic tree Pistacia lentiscus, myrrh from shrubs of Commiphora or sandarac resin from Tetraclinis articulate. Other well-known resins are pine rosin (from pines and conifers), produced from fresh liquid resin by vaporization of terpene components; shellac, secreted by the female lac bug (Lacifer lacca) on trees in the forests of India and Thailand; or propolis, consisting largely of resins collected from poplars and conifers and used by honey bees to seal gaps in their hives. Finally, ambers (also called resinite) from coniferous and other tree species ${ }^{3}$ and tragacanth, a polysaccharide gum extracted from several species of leguminous plants of the genus Astragalus (which yields a sap-like material used in Medicine), can also be included in the resins category.

\section{Composition}

The resin produced by most plants is composed mainly of terpenes and their derivatives. The most common in resins are bicyclic terpenes (namely $\alpha$-pinene, $\beta$-pinene, $\delta$ - 3 carene and sabinene), followed by monocyclic terpenes (e.g., limonene and terpinolene) and -in smaller amounts- by tricyclic ones (such as sesquiterpenes, longifolene, caryophyllene and $\delta$-cadinene).

Almost all resins also contain a high proportion of resin acids. These are closely related to the terpenes, if they derive from them through partial oxidation. Examples of resin acids are communic, abietic (sylvic acid) and boswellic acids (Figure 1).

Amber is heterogeneous in composition, but consists of a macromolecule formed by free radical polymerization of several precursors from the labdane family (e.g., communic acid, cummunol and biformene).,5 These labdanes are diterpenes and trienes, equipping the organic skeleton with three alkene groups for polymerization. Amber also contains succinoabietic acid. Abietic acid can be extracted from rosin by means of hot alcohol and, upon oxidation, yields trimellitic, isophthalic and terebic acids. Boswellic acids are a series of pentacyclic triterpene molecules produced by plants in the genus Boswellia. An analogous terpenoid composition is also exhibited by com-

\author{
Pablo Martín-Ramos ${ }^{1 *}$, \\ Ignacio Alonso Fernández- \\ Coppel ${ }^{2}$, Norlan Miguel \\ Ruíz-Potosme ${ }^{3}$, Jesús \\ Martín-Gil ${ }^{4}$ \\ 'Department of Agricultural and \\ Environmental Sciences, EPS, Instituto \\ de Investigación en Ciencias \\ Ambientales (IUCA), University of \\ Zaragoza, Carretera de Cuarte, $s / n$, \\ 22071 Huesca, SPAIN. \\ ${ }^{2}$ Engineering of Manufacturing \\ Processes group, School of Industrial \\ Engineering, University of Valladolid, C/ \\ Francisco Mendizábal 1, 47014 \\ Valladolid, SPAIN. \\ ${ }^{3}$ Universidad Europea Miguel de \\ Cervantes. C/Padre Julio Chevalier 2, \\ 47012 Valladolid, SPAIN. \\ ${ }^{4}$ Agriculture and Forestry Engineering \\ Department, ETSIIAA, Universidad \\ de Valladolid, Avenida de Madrid 44, \\ 34004 Palencia, SPAIN. \\ Correspondence \\ Pablo Martín-Ramos \\ Department of Agricultural and \\ Environmental Sciences, EPS, \\ Instituto de Investigación en Ciencias \\ Ambientales (IUCA), University of \\ Zaragoza, Carretera de Cuarte, s/n, \\ 22071 Huesca, SPAIN. \\ Email: pmr@unizar.es \\ Ph.no: +34974292668; \\ Fax: +34974239302 \\ History \\ - Submission Date: 14-12-2017; \\ - Review completed: 02-02-2018; \\ - Accepted Date: 06-02-2018.
}

DOI : 10.5530/bems.4.1.2

Article Available online

http://www.bemsreports.org

Copyright

( 2018 Phcog.Net. This is an open-access article distributed under the terms of the Creative Commons Attribution 4.0 International license.
Cite this article : Martín-Ramos P, Fernández-Coppel IA, Ruíz-Potosme NM, Martín-Gil J. Potential of ATR-FTIR Spectroscopy for the Classification of Natural Resins. BEMS Reports, 2018;4(1):3-6. 
mercial samples of Mexican copal-lágrima (Bursera fagaroides) due to the presence of boswellic acids. ${ }^{6}$ Other interesting white Mexican copals are those obtained from the Bursera jorullensis and Bursera linanoe trees. ${ }^{6,7}$

\section{Classifications of resins}

Natural resins can be classified by genera. Thus, the Bursereae -which is further split into Boswelliinae and Burserinae subtribes- contains Bursera (copal), Boswellia (frankincense) and Commiphora (myrrh).

Natural resins may also be categorized according to their age: recent resins from growing or standing trees (e.g., rosin); recent fossil resins (e.g., copal); and fossil resins (amber). ${ }^{1}$

Hardness has been used as a grouping criterion too: soft resins (dammar, mastic, sandarac) and hard resins (Madagascar and Zanzibar copals). ${ }^{8,9}$

Alternatively, the cataloguing can be conducted according to their solubility in specific solvents: spirit soluble (shellac, rosin, sandarac); turpentine soluble (dammar and mastic); and oil soluble (copal from Congo). ${ }^{1}$

On the other hand, natural resins may also be organized according to their terpene composition: abietane diterpenoids (rosin); labdane diterpenoids (sandarac and copal); and triterpenoids (dammar and almaciga). ${ }^{10}$

Nevertheless, in spite of aforementioned suggested classifications, the identification of natural resins is still an open problem, not only because of their large number (when the resin comes from tropical countries this number may run into hundreds), complexity and variety of their compositions (many of which are unknown), but also because they frequently change with ageing due to oxidation or polymerization processes. ${ }^{11}$

\section{ATR-FTIR spectroscopy as a classification tool}

Infrared spectroscopy is a valuable method for the classification of organic materials. Complex natural materials produce overlapping spectral bands resulting in a blended, yet representative, plot which may be used to identify a material. Pure synthetic resins produce vibrational bands which are readily identifiable by Fourier Transform Infrared spectroscopy (FTIR), a fact that led to a first classification attempt by Derrick et al. ${ }^{12,13}$ Nevertheless, traditional transmission-based FTIR involves the use of $\mathrm{KBr}$ pellets and liquid cells, which has some drawbacks. These disadvantages can be overcome by resorting to ATR (Attenuated Total Reflection), which enables all sort of samples (e.g., solids, liquids, powders, pastes, pellets, slurries, fibres, etc.) to be examined without further preparation in a fast, reliable and cost-effective way. ${ }^{14}$ This technique is based on the attenuation effect of light when it is internally reflected at an interface between a high refractive index material (an internal reflection element) and an infrared absorbing low refractive index material (the sample). The light extends into the later as an evanescent wave with a depth of penetration typically between 0.5 and $2 \mu \mathrm{m}$, and the beam -after one or several reflections- is then collected by a detector as it exits the crystal. ${ }^{15}$ The accessibility of ATR-FTIR and its high reproducibility has led to a substantial use by the scientific community.

\section{MATERIALS AND METHODS}

In this study, four resins were characterized: copal blanco from Chiapas, Mexico; myrrh from the region south of the Gulf of Aden (where it is named mur or mulmul); tragacanth from Turkey; and shellac from India. All samples were acquired in situ at local dealers. Their infrared spectra were recorded with a Thermo Scientific (Waltham, MA, USA) Nicolet iS50 FT-IR spectrometer, equipped with an in-built diamond ATR system, with a $1 \mathrm{~cm}^{-1}$ spectral resolution and 64 scans.

The other natural resins spectra were obtained from a bibliographical survey or from IRUG (Infrared and Raman Users Group) spectral database (www.irug.org).

\section{RESULTS}

The ATR-FTIR spectra of white copal, tragacanth, myrrh and shellac resins are shown in Figure 2. Their bands have been put in relation with those of other resins reported in the literature (see Table 1). Band assignations are summarized in Table 2.

The various types of natural resins exhibit several important spectral features in the infrared region. Resins can be distinguished from carbohydrates, waxes and oils by the presence of two bands: one between 1650 $\mathrm{cm}^{-1}$ and $1633 \mathrm{~cm}^{-1}$ and the other between $1260 \mathrm{~cm}^{-1}$ and $1238 \mathrm{~cm}^{-1}$. The first is due to $v(\mathrm{C}=\mathrm{C})$ vibrations and the second is associated to $\delta(\mathrm{C}-\mathrm{H})$ vibrations. Another distinguishing band that all resins share is a strong carbonyl $(\mathrm{C}=\mathrm{O})$ stretch at $1738-1694 \mathrm{~cm}^{-1}$. This band broadens with resin degradation and oxidation, but the band maximum remains within this wavenumber region. Bands in the fingerprint region are characteristic for each particular resin and may be used to distinguish them (e.g., $879 \mathrm{~cm}^{-1}$ for true copall ${ }^{16}$ or $725 \mathrm{~cm}^{-1}$ for myrrh).

In agreement with the literature, ${ }^{12,17}$ the frequencies at around $1700 \mathrm{~cm}^{-1}$ were chosen as a criterion for ordering and grouping the different resins into three main families: those which absorb at lower wavenumbers, between 1690 and $1710 \mathrm{~cm}^{-1}$, due to the presence of carboxylic acids (juniper, sandarac, black copal, Madagascar copal, dammar, rosin, pitch, mastic and Baltic amber); those with bands at wavenumbers between 1713 and $1727 \mathrm{~cm}^{-1}$, associated with phenol group (spinifex and mopamopa) or ketone group (white copal, tragacanth and frankincense); and

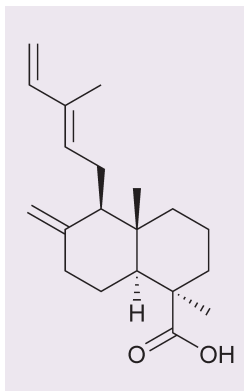

Communic acid

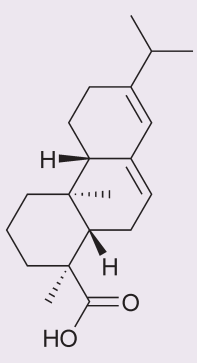

Abietic acid

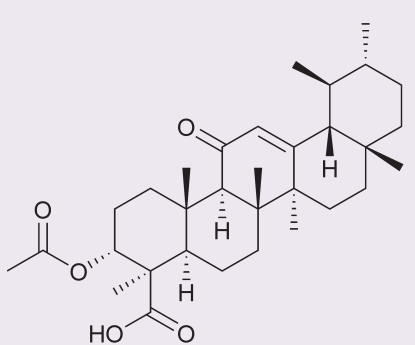

3-O-acetyl-11-keto- $\beta$-boswelic acid
Figure 1. Examples of resin acids.
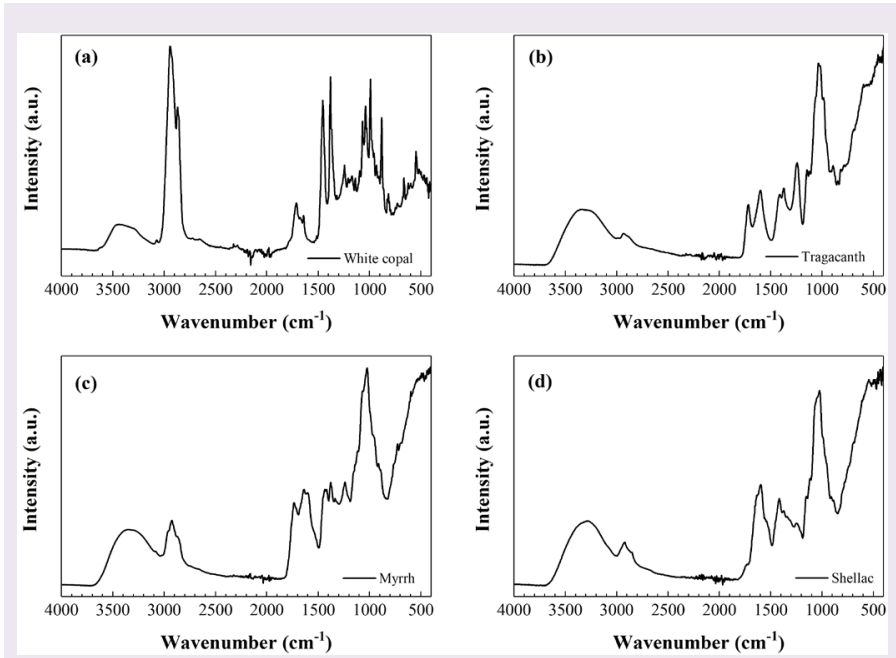

Figure 2. ATR-FTIR spectra of (a) white copal, (b) tragacanth, (c) myrrh and (d) shellac resins. 
Table 1: Main band wavenumbers in the infrared spectra of various resins (in $\mathrm{cm}^{-1}$ ).

\begin{tabular}{|c|c|c|c|c|c|c|c|c|c|c|c|c|}
\hline & Sandarac ${ }^{12}$ & Black copal ${ }^{12}$ & Pine pitch ${ }^{19}$ & Amber ${ }^{4}$ & $\operatorname{Rosin}^{12}$ & Mastic $^{13}$ & White copal & Tragacanth & Frank incense $\mathrm{e}^{20}$ & Myrrh & Shellac & Propolis ${ }^{21}$ \\
\hline 1 & 3079 & 3079 & 3070 & 3076 & & & 3477 & 3335 & 3423 & 3348 & 3277 & \\
\hline 2 & 2933 & 2933 & 2931 & 2927 & 2936 & 2949 & 2943 & 2932 & 2929 & 2925 & 2921 & 2930 \\
\hline 3 & 2873 & 2873 & 2869 & 2867 & 2870 & 2874 & 2868 & & & & 2854 & 2873 \\
\hline 4 & 1694 & 1694 & 1694 & 1696 & 1697 & 1707 & 1713 & 1716 & 1718 & 1732 & 1738 & $1740^{*}$ \\
\hline 5 & 1643 & 1643 & & 1643 & 1650 & 1650 & 1641 & & 1658 & 1635 & 1633 & 1640 \\
\hline 6 & & & 1607 & & 1612 & & & 1600 & & & 1597 & 1598 \\
\hline 7 & 1497 & & 1515 & & 1496 & & & & & & & \\
\hline 8 & 1449 & 1449 & 1453 & 1454 & & 1459 & 1453 & 1410 & 1456 & 1435 & 1417 & \\
\hline 9 & 1329 & 1329 & 1379 & 1384 & 1365 & & 1379 & 1371 & 1377 & 1378 & 1373 & 1377 \\
\hline 10 & 1236 & 1228 & 1243 & & 1239 & 1245 & 1242 & 1242 & 1242 & 1238 & 1247 & 1228 \\
\hline 11 & 1153 & 1149 & 1125 & 1159 & 1130 & 1161 & 1137 & 1145 & & & 1150 & 1136 \\
\hline 12 & & & 1114 & & 1107 & 1115 & 1095 & 1120 & & & 1112 & \\
\hline 13 & & & & & & & 1067 & & 1078 & & & 1078 \\
\hline 14 & & & 1033 & 1024 & & 1046 & 1036 & 1034 & 1045 & 1023 & 1023 & 1038 \\
\hline 15 & 972 & & & 975 & 980 & 1008 & 989 & & & & & 989 \\
\hline 16 & 909 & & 909 & & 910 & & & & & & 909 & 920 \\
\hline 17 & 856 & 889 & & 887 & & & 879 & 892 & & & & \\
\hline 18 & 823 & & & & 823 & 837 & 819 & 846 & & & & 836 \\
\hline 19 & & & & 744 & & & & & & 725 & & \\
\hline 20 & & & & & & 580 & & 595 & & 597 & 599 & \\
\hline 21 & & & & 540 & & & 547 & 521 & & & 542 & \\
\hline 22 & & & & & & & 500 & 499 & & 494 & 495 & \\
\hline 23 & & & & & & & 473 & & & 475 & 483 & \\
\hline 24 & & & & & & & 455 & 455 & & & 454 & \\
\hline 25 & & & & & & & 438 & 440 & & 440 & 446 & \\
\hline 26 & & & & & & & & 429 & & 422 & 421 & \\
\hline
\end{tabular}

* Band not always present: it depends on the origin of the propolis. Its presence has been associated to 3,7-dihydroxy-5-methoxyflavone ${ }^{22}$ or a chemical interaction with hemicellulose from wood. ${ }^{23 .}$

\begin{tabular}{cccc} 
Table 2: Infrared band assignments & & \\
Band & Assignment & Band & Assignment \\
\hline 1 & $v(\mathrm{O}-\mathrm{H})$ & 12 & O-H group, $v(\mathrm{C}-\mathrm{O}-\mathrm{C})$ \\
2 & $v(\mathrm{C}-\mathrm{H})$ from $\mathrm{CH}_{3}$ and $\mathrm{CH}_{2}$ & 13 & $v(\mathrm{C}-\mathrm{O}-\mathrm{C})$ \\
3 & $v(\mathrm{C}-\mathrm{H})$ from $\mathrm{CH}_{3}$ & 14 & $v(\mathrm{C}-\mathrm{O})$ \\
4 & Ketone, ester & 15 & $\mathrm{C}-\mathrm{O}$ bonds \\
5 & $v(\mathrm{C}=\mathrm{C}) /$ exocyclic methylene groups. Typical of resins & 16 & $\delta\left(\mathrm{C}=\mathrm{CH}_{2}\right)$ \\
6 & $v(\mathrm{C}=\mathrm{C})$ aromatic ring $/ v(\mathrm{C}=\mathrm{O})$ amide & 17 & Exocyclic methylene groups. \\
7 & $v(\mathrm{C}=\mathrm{C})$. Typical of phenolic resins & 18 & Typical of phenolic resins (after heating) \\
8 & $\delta(\mathrm{CH}), \delta\left(\mathrm{CH}_{3}\right)$ & 19 & $1,2-$ cis-disubstituted olefin. Typical of myrrh \\
9 & $\delta\left(\mathrm{CH}_{3}\right)$ & 20 & $\delta(\mathrm{C}-\mathrm{H})$ in the furan ring \\
10 & $\delta(\mathrm{C}-\mathrm{H}), v(\mathrm{C}-\mathrm{O}-\mathrm{H})$. Typical of resins & 21 & Unsaturated bonds \\
11 & $v(\mathrm{C}-\mathrm{O}-\mathrm{C})$, esters & &
\end{tabular}

those with bands located at higher wavenumbers, between 1731-1738 $\mathrm{cm}^{-1}$, because of ester group (myrrh and shellac).

When -for the first of aforementioned families- the comparison of that single band is extended to the whole spectrum, a close correspondence for rosin and mastic was readily found (revealed by a high correlation value, see Table 3), which would allow their differentiation from the other two resins (sandarac and black copal).

This finding opened the possibility of splitting the first family into two sub-families: those with communic acids (sandarac, copal and ambers) and those with abietic acid (rosin and mastic). 
Table 3: Correlation matrix

\begin{tabular}{cccccccccc} 
& Rosin & Pitch & Sandarac & Black copal & Mastic & White copal & Frankincense & Myrrh & Shellac \\
\hline Rosin & 1.000 & 0.895 & 0.900 & 0.903 & 0.906 & 0.903 & 0.885 & 0.885 & 0.899 \\
\hline
\end{tabular}

\section{DISCUSSION}

The proposed classification of the resins into families is based on the frequencies of their infrared spectra, and such spectra can be obtained either by FTIR or by ATR-FTIR, which is known to lead to small shifts in peak positions. ${ }^{18}$ Four spectra were obtained by ATR-FTIR and compared against analogous IRUG database spectra (obtained by $\mathrm{KBr}$ method). Good correlation was observed, with shifts below $3 \mathrm{~cm}^{-1}$ in all cases and was comparable to those found amongst samples from different laboratories in the IRUG database. Special attention was paid to the differences that may arise in the wavenumbers of the band(s) around $1700 \mathrm{~cm}^{-1}$, which were taken as a classification key: for fresh samples, the maximum difference was $2 \mathrm{~cm}^{-1}$. Another was the case for aged or heated samples, but the incidence of such interferences can be easily anticipated by checking the disappearance upon aging of the bands at 1643 and 1607 $\mathrm{cm}^{-1}$, attributed to $v(\mathrm{C}=\mathrm{C})$ vibrations, and the increased absorption upon heating of $v(\mathrm{C}-\mathrm{O}-\mathrm{C})$ and $v(\mathrm{C}-\mathrm{O}-\mathrm{H})$ bands at 1153 and $1240 \mathrm{~cm}^{-1}$, respectively.

The purity degree would also have a remarkable impact on the resins' absorption bands. For instance, seedlac (which contains 3-5\% impurities) would absorb at $1714 \mathrm{~cm}^{-1}$, whereas when it is purified by thermal treatment or by solvent extraction (resulting in the so-called shellac) it absorbs at $1731 \mathrm{~cm}^{-1}$ and even at $1738 \mathrm{~cm}^{-1}$ (if it is very pure).

\section{CONCLUSION}

ATR-FTIR spectroscopy can provide a useful approach to allow the categorization of resins into families based on a set of band positions (in particular the bands located at around $1700 \mathrm{~cm}^{-1}$ ). The vibrational features suggest the differentiation of at least four main families: (I) those with communic acids (including sandarac, black copal, pine pitch and ambers), which absorb between 1690 and $1696 \mathrm{~cm}^{-1}$; (II) those with abietic acid (consisting of rosin and mastic), with absorption bands between 1697 and $1710 \mathrm{~cm}^{-1}$; (III) those with ketone group (encompassing white copal, tragacanth and frankincense), which absorbs between 1713 and $1727 \mathrm{~cm}^{-1}$; and (IV) those with ester group (comprising myrrh, shellac, and propolis), which absorbs between $1731-1738 \mathrm{~cm}^{-1}$.

\section{ABBREVIATION USED}

FTIR: Fourier Transform Infrared spectroscopy; ATR: Attenuated Total Reflection.

\section{CONFLICT OF INTEREST}

The authors declare no conflict of interest.

\section{REFERENCES}

1. VV.AA. Natural resins, modified natural resins and bituminous materials. In: NIIR Board (Ed.) The complete technology book on printing inks. Asia Pacific Business Press Inc. New Delhi, India. 2003;640.

2. Nussinovitch A. Plant gum exudates of the world: sources, distribution, properties, and applications, (CRC Press/Taylor Francis, Boca Raton, FL, 2010) pp. 427.

3. Grimaldi DA, Amber: window to the past, (Harry N. Abrams Publishers in association with the American Museum of Natural History. New York, USA. 1996;216.
4. Abduriyim A, Kimura H, Yokoyama Y, Nakazono H, Wakatsuki M, Shimizu T, Tansho $\mathrm{M}$, et al. Characterization of "Green Amber" with infrared and nuclear magnetic resonance spectroscopy. Gems and Gemology. 2009;45(3):158-77.

5. Barrero AF, Herrador M, Arteaga P, Arteaga JF, Arteaga AF. Communic acids: occurrence, properties and use as chirons for the synthesis of bioactive compounds. Molecules. 2012;17(2):1448-67.

6. Gigliarelli G, Becerra JX, Curini M, Marcotullio MC. Chemical composition and biological activities of fragrant Mexican copal (Bursera spp.). Molecules. 2015;20(12):22383-94

7. Fernández López J, Programas iconográficos de la pintura barroca sevillana del siglo XVII, (Universidad de Sevilla, Sevilla, Spain. 2002;344.

8. Matsukawa N. Natural resins and balsams. The Encyclopedia of painting materials (2002). Available at: <http://www.cad-red.com/mt2/resins.html>. Last accessed: February 12, 2018.

9. Taniguchi $Y$, Taniguchi H, Yamada M, Matsukura $Y$, Koizumi H, Furihata K, et al. Analysis of the components of hard resin in hops (Humulus lupulus L.) and structural elucidation of their transformation products formed during the brewing process. Journal of Agricultural and Food Chemistry. 2014;62(47):11602-12.

10. Romero-Noguera J. Biodeterioro fúngico y bacteriano de las resinas terpénicas utilizadas en pintura y otras artes plásticas, (Universidad de Granada, Granada, Spain. 2007;233.

11. Cartoni G, Russo MV, Spinelli F, Talarico F. GC-MS characterisation and identification of natural terpenic resins employed in works of Art. Annali di Chimica. 2004;94(11):767-82

12. Derrick M. Fourier transform infrared spectral analysis of natural resins used in furniture finishes. Journal of the American Institute for Conservation. 1989;28(1):43-56

13. Derrick M, Grzywacz C, Preusser F. FTIR analysis of finishes on Oriental style 18th century European furniture. In: N. S. Brommelle and P. Smith (Eds.) Proceedings of the Urushi Study Group. The Getty Conservation Institute, Tokyo, Japan. 1988;227-34

14. Perkin Elmer. FT-IR Spectroscopy-Attenuated total reflectance (ATR), (PerkinElmer Life and Analytical Sciences. Shelton, CT, USA. 2005;5.

15. Mirabella FM. Internal reflection spectroscopy: theory and applications, (Marcel Dekker, New York, USA. 1993;374.

16. Guiliano M, Asia L, Onoratini G, Mille G. Applications of diamond crystal ATR FTIR spectroscopy to the characterization of ambers. Spectrochimica Acta, Part A: Molecular and Biomolecular Spectroscopy. 2007;67(5):1407-11.

17. Montoro RO. Estudio espectroscópico de la formación de análogos de resinas fósiles, (Universidad Complutense de Madrid. Madrid, Spain. 2013:223.

18. Nunn S, Nishikida K. Advanced ATR correction algorithm - Application note 50581, (ThermoScientific, Madison, WI, USA. 2008;4.

19. Odegaard N, Pool M, Bisulca C, Santarelli B, Neiman M, Watkinson G. Pine pitch: new treatment protocols for a brittle and crumbly conservation problem. Objects Specialty Group Postprints. 2014;21:21-41.

20. Taha K, Elmahi RH, Hassan EA, Ahmed SE, Shyoub MH. Analytical study on three types of gum from Sudan. Journal of Forest Products and Industries. $2012 ; 1(1): 11-16$

21. Matei PM, Martin-Ramos P, Sanchez-Bascones M, Hernandez-Navarro S, Correa-Guimaraes A, Navas-Gracia LM, et al. Synthesis of chitosan oligomers/propolis/silver nanoparticles composite systems and study of their activity against Diplodia seriata. International Journal of Polymer Science. 2015;1-11.

22. Nagy M, Suchy V, Uhrin D, Ubik K, Budesinsky M, Grancai D. Constituents of propolis of Czechoslovak origin V. Chemical Papers - Chemicke Zvesti. 1988;42:691-6.

23. Wozniak M, Ratajczak I, Szentner K, Kwasniewska P, Mazela B. Propolis and organosilanes in wood protection. Part I: FTIR analysis and biological tests. Annals of Warsaw University of Life Sciences-SGGW. Forestry and Wood Technology. $2015 ; 91: 218-224$

Cite this article : Martín-Ramos P, Fernández-Coppel IA, Ruíz-Potosme NM, Martín-Gil J. Potential of ATR-FTIR Spectroscopy for the Classification of Natural Resins. BEMS Reports, 2018;4(1):3-6. 